\title{
Development of Regenerable High Capacity Boron Nitrogen Hydrides as Hydrogen Storage Materials
}

\author{
Ashok Damle \\ RTI International \\ 3040 Cornwallis Road \\ P.O. Box 12194 \\ Research Triangle Park, NC 27709 \\ Phone: 919-541-6146; Fax number: 919-541-8002 \\ E-mail: adamle@rti.org \\ DOE Technology Development Manager: Grace Ordaz \\ [Phone: 202-586-8350; E-mail: grace.ordaz@ee.doe.gov ] \\ DOE Project Officer: James Alkire \\ [Phone: 303-275-4795; E-mail: james.alkire@go.doe.gov]
}

Contract Number: DE-FG36-05GO15005

Subcontractors:

Intematix, Corporation

Fremont, California

Start Date: 12/01/2004 (Contract signature date - 03/15/2005)

Projected End Date: 11/30/2010

\section{Objectives}

- Evaluate approaches for complete and fast release of hydrogen from ammoniaborane at moderate temperatures and partial hydrogen release at low temperatures

- Develop an efficient on-board hydrogen extraction process

- Design an on-board hydrogen storage and extraction system

- Demonstrate individual steps involved in ammonia-borane synthesis starting from the ammonia-borane decomposition products for their recycle

- Demonstrate regeneration energy efficiency $>60 \%$ with $>70 \%$ yield of ammonia borane

- Scale-up the ammonia-borane regeneration process

- Design, develop, and demonstrate prototype (1 kg hydrogen capacity) hydrogen extraction system with $>9 \mathrm{wt} \%$ hydrogen capacity

- Determine technical and economic feasibility of utilizing ammonia-borane as an on-board hydrogen storage medium

\section{Technical Barriers}

This project addresses the following technical barriers from the Section 3.3.4 (On-Board Hydrogen Storage Technical Barriers) of the current Hydrogen, Fuel Cells, and Infrastructure Technologies Program Multi-Year Research, Development and Demonstration Plan: 
- A. Storage system weight and volume

- B. System cost

- C. Efficiency

- D. Durability/operability

- E. Charging/discharging rates

- F. Codes and standards

- G. Materials of construction

- H. Balance of plant components

- I. Dispensing technology

- J. Thermal management

- K. System life-cycle assessment

- R. Regeneration processes

- S. By-Product/Spent Material Removal

\section{Technical Targets}

This project is evaluating feasibility of using ammonia-borane $\left(\mathrm{NH}_{3} \mathrm{BH}_{3}\right)$ as an on-board hydrogen storage medium. With $19.6 \%$ by weight of hydrogen in its molecular formula, ammonia-borane has potential to meet DOE's year 2015 targets of gravimetric $(0.09 \mathrm{~kg}$ $\mathrm{H}_{2} / \mathrm{kg}$ of system weight) as well as volumetric ( $0.081 \mathrm{~kg} \mathrm{H}_{2} / \mathrm{L}$ of system volume) energy densities. Evaluation of approaches to regenerate ammonia-borane decomposition products will determine the feasibility of approaching DOE's fuel cost (\$2 to 3/GGE kg $\mathrm{H}_{2}$ ) target. Development of an efficient hydrogen extraction system will allow approaching the storage system cost $\left(\$ 67 / \mathrm{kg}\right.$ stored $\left.\mathrm{H}_{2}\right)$ target.

\section{Accomplishments:}

- Characterized non-catalytic hydrogen release from $\mathrm{AB}$ for hydrogen yield and release kinetics for $\mathrm{AB}$ decomposition at 100 to $500{ }^{\circ} \mathrm{C}$.

- Amounts of impurities produced (borazine and diborane) were determined as a function of the $\mathrm{AB}$ decomposition temperature.

- Amount of heat released during each of the decomposition step was determined.

- Demonstrated hydrogen yield of up to $16.3 \mathrm{wt} \% \mathrm{AB}$ at moderate temperature of $150{ }^{\circ} \mathrm{C}$ in the presence of catalysts.

- Established methodology and techniques for combinatorial screening of catalyst activity for dehydrogenation of $\mathrm{AB}$ and regeneration of decomposition products.

- Conducted screening of one set of catalyst compositions each for hydrogen release from ammonia borane (identified two catalyst leads) and for regeneration of decomposition products generated with loss of one mole of hydrogen/mole $\mathrm{AB}$ (identified several catalyst leads)

- Assembled bulk catalytic dehydrogenation and high pressure regeneration reactor and evaluated two metallic catalysts.

\section{Introduction}

The objective of this three-phase project is to develop synthesis and hydrogen extraction processes for nitrogen/boron hydride compounds that will permit exploitation of the high 
hydrogen content of these materials. The primary compound of interest in this project is ammonia-borane $\left(\mathrm{NH}_{3} \mathrm{BH}_{3}\right)$, a white solid, stable at ambient conditions, containing $19.6 \%$ of its weight as hydrogen. With a low-pressure on-board storage and an efficient heating system to release hydrogen, ammonia-borane has a potential to meet DOE's year 2015 specific energy and energy density targets. If the ammonia-borane synthesis process could use the ammonia-borane decomposition products as the starting raw material, an efficient recycle loop could be set up for converting the decomposition products back into the starting boron-nitrogen hydride.

\section{Approach}

This project is addressing two key challenges facing the exploitation of the boron/ nitrogen hydrides (ammonia-borane), as hydrogen storage material:

- Development of a simple, efficient, and controllable system for extracting most of the available hydrogen, realizing the high hydrogen density on a system weight/volume basis, and

- Development of a large-capacity, inexpensive, ammonia-borane regeneration process starting from its decomposition products $\left(\mathrm{BNH}_{\mathrm{x}}\right)$ for recycle.

During Phase I of the program both catalytic and non-catalytic decomposition of ammonia borane are being investigated to determine optimum decomposition conditions in terms of temperature for decomposition, rate of hydrogen release, purity of hydrogen produced, thermal efficiency of decomposition, and regenerability of the decomposition products. The non-catalytic studies provide a base-line performance to evaluate catalytic decomposition. Utilization of solid phase catalysts mixed with ammonia-borane was explored for its potential to lower the decomposition temperature, to increase the rate of hydrogen release at a given temperature, to lead to decomposition products amenable for regeneration, and direct catalytic hydrogenation of the decomposition products.

Two different approaches of heating ammonia-borane are being investigated: a) "heat to material approach" in which a fixed compartmentalized ammonia-borane is heated by a carefully controlled heating pattern, and b) "material to heat approach" in which a small amount of ammonia-borane is dispensed at a time in a fixed hot zone. All stages of AB decomposition are exothermic which should allow the small "hot zone" used in the second approach for heating to be self-sustaining. During the past year hydrogen release efforts focused on the second approach determining the amount of hydrogen released, kinetics of hydrogen release, and the amounts of impurities released as a function of AB decomposition temperature in the "hot zone."

\section{Results}

- The amount of hydrogen released, kinetics of hydrogen release, and the amounts of impurities produced were determined as a function of decomposition temperature in a "drop tube" reactor. The results are summarized in Table below.

- Heat released during each of the three stages of $\mathrm{AB}$ decomposition at $93{ }^{\circ} \mathrm{C}, 130$ ${ }^{\circ} \mathrm{C}$, and $480{ }^{\circ} \mathrm{C}$ respectively was determined using differential scanning calorimetry and was found to be 447, 333, and $139 \mathrm{~J} / \mathrm{g}$ of AB respectively. 
- First mole of hydrogen $(1 / 3)$ is released by $100{ }^{\circ} \mathrm{C}$, the second mole of hydrogen is released by $150{ }^{\circ} \mathrm{C}$.

- Increasing temperature from 150 to $400{ }^{\circ} \mathrm{C}$ results in faster release of hydrogen but with very little increase in amount

- About 5/6 ( 83\%) hydrogen is released at $500{ }^{\circ} \mathrm{C}$ confirmed by residue analysis indicating $\sim \mathrm{BNH}$ elemental distribution

- Borazine was predominantly observed during second stage of hydrogen release, whereas, diborane was observed only during the second stage.

- Borazine appears to be stable even at $500{ }^{\circ} \mathrm{C}$, whereas, diborane appears to be decomposed at $225{ }^{\circ} \mathrm{C}$ or greater decomposition temperature.

- Established methodology and techniques for combinatorial screening of catalyst activity for dehydrogenation of $\mathrm{AB}$ and regeneration of decomposition products by analyzing material color change as a result of hydrogenation/dehydrogenation.

- Conducted screening of one set of catalyst compositions each for hydrogen release from ammonia borane (identified two catalyst leads) and for regeneration of decomposition products generated with loss of one mole of hydrogen/mole AB (identified several catalyst leads)

- Assembled bulk catalytic dehydrogenation and high pressure regeneration reactor and evaluated two metallic catalysts. Although catalysts were found to increase hydrogen yield to 2.5 moles (83\%) at $150{ }^{\circ} \mathrm{C}$ no hydrogenation activity was seen.

\section{Conclusions and Future directions}

The hydrogen release studies have confirmed the potential of ammonia-borane for meeting U.S. DOE's 2015 hydrogen storage density targets. Additional catalysts identified using combinatorial synthesis technology will be evaluated for direct catalytic hydrogenation of ammonia-borane decomposition products. Alternative approaches for regeneration of decomposition products based on liquid phase chemical processing will be investigated.

\section{FY2008 Publications/presentations}

1. Damle, A.S., "Development of Regenerable High Capacity Boron Nitrogen Hydrides as Hydrogen Storage Materials," FreedomCAR Hydrogen Storage Technical Team Review Meeting, April 17, 2008.

2. Damle, A.S., "Development of Regenerable High Capacity Boron Nitrogen Hydrides as Hydrogen Storage Materials," U.S. DOE/EERE Hydrogen Program Review Meeting, June 9, 2008. 
Table 1: Hydrogen release characteristics at different AB decomposition temperatures.

\begin{tabular}{|c|c|c|c|c|c|}
\hline $\begin{array}{c}\text { Decomp. } \\
\text { Temp., oC }\end{array}$ & $\begin{array}{c}\mathbf{H}_{2} \text { Released } \\
\text { AB }\end{array}$ & $\begin{array}{c}\text { H}_{2} \text { yield } \\
\text { Wt \% AB }\end{array}$ & $\begin{array}{c}\text { Time for } \\
\text { Release, s }\end{array}$ & $\begin{array}{c}\text { Borazine } \\
\text { Conc., ppm }\end{array}$ & $\begin{array}{c}\text { Diborane } \\
\text { Conc., ppm }\end{array}$ \\
\hline 100 & 1 & 6.5 & $\sim 1200$ & 1,110 & 0 \\
\hline 125 & 1.7 & 11.2 & $400-500$ & 15,200 & 320 \\
\hline 150 & 2 & 13.1 & $100-200$ & 11,800 & 390 \\
\hline 200 & 2.1 & 13.7 & $40-60$ & 11,800 & 300 \\
\hline 300 & 2.1 & 13.7 & $35-40$ & 14,300 & 0 \\
\hline 400 & 2.2 & 14.3 & $30-35$ & 11,100 & 0 \\
\hline 500 & 2.5 & 16.3 & $15-20$ & 7,200 & 0 \\
\hline
\end{tabular}

